ländischen Krebsgesellschaft e. V., Sulzbachstr. 37, 66111 Saarbrücken)“.

Nach nur wenigen Monaten in der Praxis bestätigt das Feedback von „STÜTZPUNKT“ der Saarländischen Krebsgesellschaft, wie wichtig es ist, Raum für derartige Treffen zu bieten. „Gemeinsam sind wir stark“: die Teilnehmer gewinnen ein Stück Normalität zurück, sie spüren den Zusammenhalt und das Gefühl nicht mehr alleine betroffen zu sein, gemeinsame Aktivitäten machen Mut sich auch wieder in der „normalen“ Welt zu bewegen. Es gibt Unterstützung und konkrete Hilfestellung, auch bei schwierigen The-

Forum 2017 · 32:363

DOI 10.1007/s12312-017-0312-0

Online publiziert: 14. August 2017

(c) Springer Medizin Verlag GmbH 2017 men. $\mathrm{Zu}$ guter Letzt, aber nicht weniger wichtig: sie stoßen auf Verständnis der anderen Betroffenen und blicken im Idealfall wieder mit Zuversicht in die Zukunft.

STÜTZPUNKT freut sich über weitere Teilnehmer.

\section{Informationen zu „STÜTZPUNKT“ im Überblick}

- Treffen für junge Krebsbetroffene bis 39 Jahre

- Termine: immer am letzten Mittwoch im Monat, von 19-21 Uhr
- Treffpunkt: Geschäftsräume der Saarländischen Krebsgesellschaft e. V., Sulzbachstr. 37, 66111 Saarbrücken

- Anfragen über info@saarlaendischekrebsgesellschaft.de oder telefonisch unter 0681-95906673

\section{Korrespondenzadresse}

Saarländische Krebsgesellschaft e.V.

Sulzbachstraße 37

66111 Saarbrücken, Deutschland

Tel: 0681 - 959066 - 73

E-Mail: info@saarlaendische-krebsgesellschaft.de

www.saarlaendische-krebsgesellschaft.de

\title{
Peter N. Meier neuer Vorsitzender der Niedersächsischen Krebsgesellschaft
}

Bei der Mitgliederversammlung am 14.06. 2017 wurde Dr. med. Peter N. Meier, FASGE FEBG, Chefarzt der Klinik für Gastroenterologie im DIAKOVERE Henriettenstift Hannover zum neuen Vorsitzenden der Niedersächsischen Krebsgesellschaft gewählt. Der bisherige stellvertretende Vorsitzende ist Nachfolger von Dr. med. Renate Bendel, die dieses Amt 20 Jahre inne hatte und im Februar 2017 überraschend verstarb. Zum neuen stellvertretenden Vorsitzenden wählten die Mitglieder der Niedersächsischen Krebsgesellschaft PD Dr. med. Hartmut Kirchner, Chefarzt der Klinik für Hämatologie, Onkologie und Palliativmedizin im KRH Klinikum Siloah.

\section{Korrespondenzadresse}

\section{Carsten Pfeil}

Niedersächsische Krebsgesellschaft e.V.

Königstraße 27

30175 Hannover

Tel. 0511 - 3885262

pfeil@nds-krebsgesellschaft.de

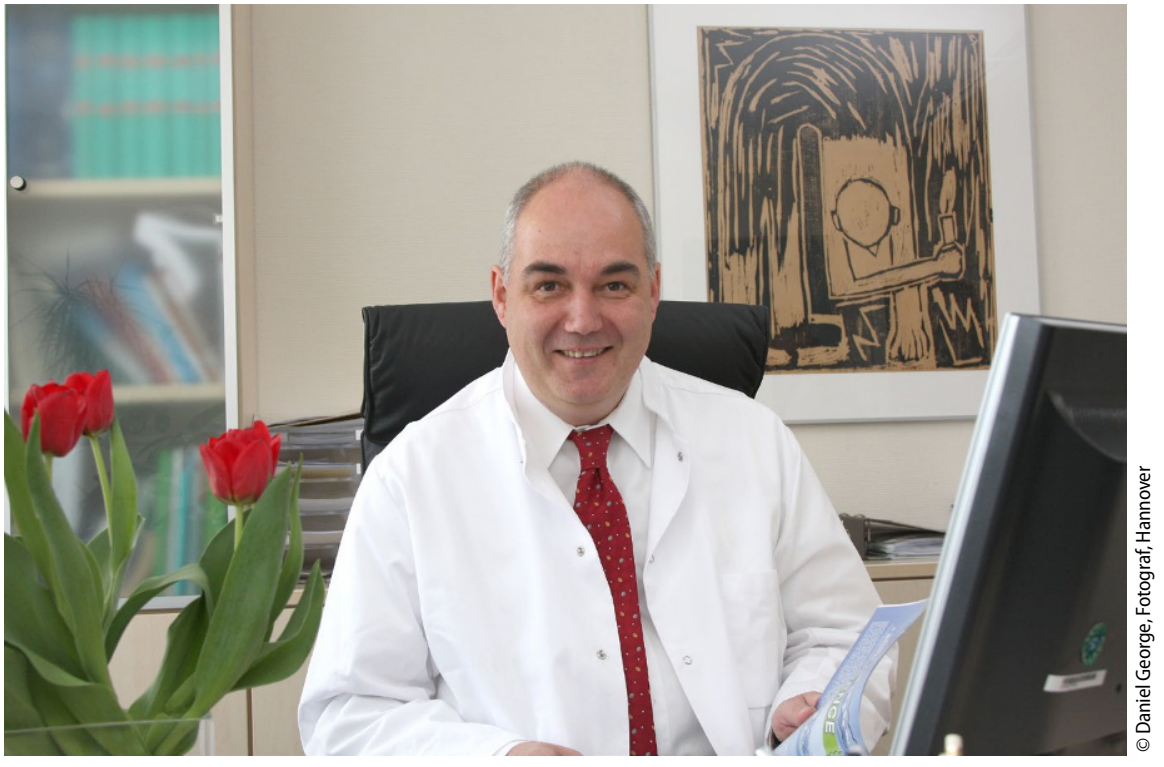

$\Delta$ Dr. med Peter N. Meier 